\title{
A survey on critical factors influencing agricultural insurance
}

\author{
Naser Azad ${ }^{\mathrm{a}}$, Gholamreza Heidari Kord Zangeneh ${ }^{\mathrm{a}}$, Seyed Mohsen SeyedAliAkbar ${ }^{\mathrm{a}}$ and Ali Valipour ${ }^{\mathrm{b}}$
}

${ }^{a}$ Department of Management, Islamic Azad University, South Tehran Branch, Tehran, Iran

${ }^{b}$ Master student, Department of Management, Islamic Azad University, South Tehran Branch, Tehran, Iran

\section{CHRON I C L E}

\section{Article history:}

Received June 25, 2012

Received in revised format

28 October 2012

Accepted 30 October 2012

Available online

November 22012

Keywords:

Agricultural products

Insurance

Factor analysis

\section{A B S T R A C T}

Agricultural business is a very high-risk job and an increase demand for agricultural products from one side and steady increase in production cost and weather changes, on the other side, have motivated many to use insurance for agricultural products. Insurance plays an important role in influencing crop production and insured satisfaction or farmers. The purpose of this research is to find critical components in agricultural insurance. Based on an exploration of the literature review and interviews, the proposed study of this paper extracts 24 variables and using factor analysis, we select the most important factors, which are grouped in seven categories. The implementation of our factor analysis has revealed uncertainty, moderator, market equilibrium, risky environment, empowering factor, education, training, structural hazards and natural ecosystems as the most important factors influencing agricultural industry.

\section{Introduction}

Agricultural business is a very high-risk job and an increase demand for agricultural products from one side, steady increase in production cost and weather changes, on the other side, have motivated many to use insurance for agricultural products (Mahul \& Vermersch, 2000; Wong, 2002; Hau, 2006). During the past few years, there have been several studies associated with agricultural products. Juyun (2010) discussed how to deal with non-systemic risk in agricultural industry using agricultural insurance. He explained that China's agricultural insurance did not have financial subsidy model, policies lack effective security as well as a comprehensive policies of agricultural insurances. This makes it difficult to make some changes on the situation of insufficient effective demand and supply (Hart et al., 2001; Machnes, 1995). Therefore, the government of China must make some clear optimization path of support model, optimize the financial subsidy, build an efficient monitoring mechanism among peasants. Juyun (2010) further discussed that it is necessary to have good planning for reaching virtuous cycle among farmers, agriculture, agricultural insurance, agricultural credit, promote the sustainable development of agricultural insurance. 
Yang (2010) reviewed agricultural risk management strategies implemented by farm households and some of the unique problems related to agricultural insurance. More specifically, he discussed the experience of developed countries to make the case for why such methods could not work well in lower-income countries. Yang (2010) introduced some innovations, which implement index-based insurance products, and presented a pricing model for weather index derivatives deduced with utilitybased pricing. Zeng and $\mathrm{Mu}$ (2010) investigated China's policy-oriented agricultural insurance development effectiveness by studying policy objectives as the evaluation criteria, and excavated out the main existence and potential problems.

Yuanchang and Jiyu (2010) analyzed the optimal boundary of the fiscal subsidies based on the welfare loss framework in agricultural insurance. They reduced the benefit loss due to asymmetric information, optimized the efficiency of fiscal transfers, enhanced the farmers' welfare, and gave insights on how to promote our political subsidies in agricultural insurance. Dick and Wang (2010) in a comprehensive survey considered international experiences in developing agricultural insurance, the governments' interventions and investigated the relationship between the rapid expansion of the Chinese agricultural insurance market and these issues.

Qing-song (2010) analyzed characteristics of farmer behavior in agricultural insurance and the factors influencing their behavior. He analyzed the risk preferences of individual farmer based on VonNorman-Morgenstern utility model and reported that under the present stage, different factors influence agricultural insurance behavior. Sai et al. (2010) explored some important factors, which influence a the farmers buying or not buying agricultural insurance and provided some suggestion on how to develop the agricultural insurance in China for policy makers.

Cole and Gibson (2010) described crop revenue insurance, discussed the relative importance of different factors in successful contract writing and presented a robust analytical procedure for assessing combined crop yield and price risks. Cao and Zhang (2010) analyzed insurance companies and mutual relationships between the government, analyzed how to revise its strategy to achieve a balanced process and proposed some policy recommendations to optimize the level of three wellbeings. Wang et al. (2010) investigated the suitability of the Survival Analysis model for the crop insurance program design. They focused mainly on the catastrophic risk premium rate estimates under the condition of 70\% yield coverage for rice, corn and sorghum in Panjin of Liaoning province, China. Their results indicated that the estimated premium rates for each crop were consistent with the currently prevailed crop insurance premium rate in Panjin.

Qingshui and Xuewei (2010) performed an empirical based on the questionnaire survey and statistical data over the peiord 1998- 2009, and then reported four problems on agricultural insurance development and five original causes. Yang et al. (2010) investigated the nonparametric density function model and estimated the probability of yield loss rate at 3 proposed levels for grain crop, wheat, corn, rice and cotton respectively from 13 provinces in the Major Grain-Producing Area. They concluded that the current crop insurance coverage level under normal years could not generate an efficient inducement for farmers to buy insurance contracts. They suggested that it was essential to carry out positive and conditional forced insurance, provided a larger portion of premium subsidy to the Major Grain-Producing Area by central government and improved the basic agricultural production conditions to expand crop insurance participation.

Pasaribu (2010) discussed the agricultural development policy of Indonesian government to reach self-sufficiency in rice. However, he discussed that rice production growth was critical to increase availability, accessibility, and affordability following the effect of global climate change (Nelson \& Loehman, 1987). He formulated a model to obtain knowledge about insurance application and reported that rice farm insurance scheme could successfully work with three-way coordination active roles of the government, the farmers and the insurance company. 


\section{The proposed study}

The proposed study of this paper investigates the impact of important factors on agricultural industry. The proposed study designs a questionnaire consists of 30 questions in Likert scale. We have used Cronbach alpha to verify the reliability of the questionnaire and it yielded 0.855 , which is well above the minimum desirable level of 0.70. Since factor analysis is sensitive against Skewness of the data, we have decided to remove four questions from the survey. Next, the implementation of factor analysis has determined seven factors where each one includes three to four variables.

\section{The results}

In this section, we present details of our survey on factor analysis.

\subsection{Uncertainty}

The first variable of the factor analysis is associated with uncertainties surrounding agricultural industry. This factor includes four variables including risk management, Control of damage by insurance, Stabilizing farmers' incomes and introducing good mechanisms for comparing risk. Cronbach alpha has been calculated as $63.3 \%$ and Table 1 shows details of our findings.

\section{Table 1}

Details of factor analysis for uncertainties surrounding agricultural industry

\begin{tabular}{|c|c|c|c|c|}
\hline Option & Factor Weight & Eigen value & \% of variance & Accumulated \\
\hline Risk Management & 0.603 & \multirow{4}{*}{6.094} & \multirow{4}{*}{27.229} & \multirow{4}{*}{27.229} \\
\hline Control of damage by insurance & 1.123 & & & \\
\hline Stabilizing farmers' incomes & 1.059 & & & \\
\hline Introducing good mechanisms for comparing risk & 0.539 & & & \\
\hline
\end{tabular}

As we can observe from the results of Table 1, in terms of uncertainty, using insurance to control damage is the most important factor followed by stabilizing farmers' incomes, risk management and introducing good mechanisms for comparing risk.

\subsection{Moderator}

The second variable of the factor analysis is associated with moderators surrounding agricultural industry. This factor includes three variables including risk diversity, risk transfer and Precautionary savings. Cronbach alpha has been calculated as 54.2\% and Table 2 demonstrates details of our investigation.

\section{Table 2}

Details of factor analysis for moderator factors in agricultural industry

\begin{tabular}{|c|c|c|c|c|}
\hline Option & Factor Weight & Eigen value & \% of variance & Accumulated \\
\hline Risk diversity & 0.621 & \multirow{3}{*}{1.914} & \multirow{3}{*}{6.379} & \multirow{3}{*}{33.608} \\
\hline Risk transfer & 0.633 & & & \\
\hline Precautionary savings & 0.735 & & & \\
\hline
\end{tabular}

The results of Table 2 show that precautionary savings is the most important factor followed by risk transfer and risk diversity as moderator in our survey.

\subsection{Market equilibrium}

Market equilibrium is the third components of factor analysis and it includes three factors where Cronbach alpha is reported as $50.2 \%$ and details are given in Table 3 as follows, 
Table 3

Details of factor analysis for market equilibrium factors in agricultural industry

\begin{tabular}{|c|c|c|c|c|}
\hline Option & Factor Weight & Eigen value & \% of variance & Accumulated \\
\hline Loan repayment capacity & 0.941 & \multirow{3}{*}{1.845} & \multirow{3}{*}{6.160} & \multirow{3}{*}{39.768} \\
\hline Help stabilize and balance the cost & 0.864 & & & \\
\hline Balancing supply & 0.835 & & & \\
\hline
\end{tabular}

As we can observe from the results of Table 3, Loan repayment capacity, Help stabilize and balance the cost and Balancing supply are three the most important factors of our investigation.

\subsection{Risky Environment}

Risky Environment is the fourth item in our survey with four factors including exposure to environmental with high risk, Exposure to environmental with low risk, existence of supportive view and imposing the law of the greater participation, less risk. In this section, Cronbach alpha is reported as $71.0 \%$ and details are given in Table 4 as follows,

\section{Table 4}

Details of factor analysis for Risky Environment in agricultural industry

\begin{tabular}{|c|c|c|c|c|}
\hline Option & Factor Weight & Eigen value & \% of variance & Accumulated \\
\hline Exposure to environmental with high risk & 0.346 & \multirow{4}{*}{1.436} & \multirow{4}{*}{4.788} & \multirow{4}{*}{44.556} \\
\hline Exposure to environmental with low risk & 0.314 & & & \\
\hline Existence of supportive view & 0.393 & & & \\
\hline The greater participation, less risk & 0.378 & & & \\
\hline
\end{tabular}

\subsection{Empowering factor}

Empowering factor is the fifth item in our investigation with four factors including exposure to environmental with high risk, Exposure to environmental with low risk, existence of supportive view and imposing the law of the greater participation, less risk. In this section, Cronbach alpha is reported as $71.0 \%$ and details are given in Table 4 as follows,

\section{Table 4}

Details of factor analysis for Risky Environment in agricultural industry

\begin{tabular}{|c|c|c|c|c|}
\hline Option & Factor Weight & Eigen value & \% of variance & Accumulated \\
\hline Distribution of risk among other insurance firms & 1.016 & \multirow{4}{*}{1.271} & \multirow{4}{*}{4.237} & \multirow{4}{*}{48.793} \\
\hline Change in credit status of insurance firms & 0.982 & & & \\
\hline Reduction in dependency of farmers to loan payers & 0.765 & & & \\
\hline Improving insurance firms' positions & 0.924 & & & \\
\hline
\end{tabular}

The results of our survey have indicated that distribution of risk among other insurance firms is the most important factor followed by change in credit status of insurance firms and Improving insurance firms' positions.

\subsection{Education and training}

Education and training is the sixth components of factor analysis and it includes three factors where Cronbach alpha is reported as 58.0\% and details are given in Table 6 as follows,

\section{Table 6}

Details of factor analysis for education and training factors in agricultural industry

\begin{tabular}{|c|c|c|c|c|}
\hline Option & Factor Weight & Eigen value & $\%$ of variance & Accumulated \\
\hline Mitigate risk & 0.726 & & & \\
\hline Forced changes in cropping patterns & 1.271 & 1.2 & 4.001 & 52.794 \\
\hline Encouraged to adopt procedures to deal with risk & 1.2 & & & \\
\hline
\end{tabular}


As we can observe from the results of Table 6, forced changes in cropping patterns is the most important factor followed by encouraged to adopt procedures to deal with risk and Mitigate risk.

\subsection{Structural hazards and natural ecosystems}

Structural hazards and natural ecosystems is the last item for the implementation of the factor analysis, which includes three factors and Cronbach alpha is reported as $58.6 \%$ and details are given in Table 7 as follows,

\section{Table 7}

Details of factor analysis for Structural hazards and natural ecosystems factors in agricultural industry

\begin{tabular}{lccccc}
\hline Option & Factor Weight & Eigen value & \% of variance & Accumulated \\
\cline { 1 - 2 } Price fluctuations & 0.494 & & & \\
\cline { 1 - 2 } Global warming and weather changes & 0.423 & & \multirow{2}{*}{3.744} & 56.538
\end{tabular}

Among the factors reported in Table 6, consolidated agricultural supply is the most important factor followed by price fluctuations and global warming.

\section{Conclusion}

In this paper, we have presented an empirical survey to detect important factors influencing agricultural production. The implementation of our factor analysis has revealed seven factors including uncertainty, moderator, market equilibrium, risky environment, empowering factor, education and training and structural hazards and natural ecosystems. In terms of uncertainty, using insurance to control damage is the most important factor followed by stabilizing farmers' incomes, risk management and introducing good mechanisms for comparing risk. Precautionary savings is the most important factor followed by risk transfer and risk diversity as moderator in our survey. Loan repayment capacity, help stabilize and balance the cost and balancing supply are three the most important factors of our investigation. Finally, in terms of risky environment in agricultural industry, distribution of risk among other insurance firms is the most important factor followed by change in credit status of insurance firms and improving insurance firms' positions.

\section{References}

Brace, N., Kemp, R., \& Snelgar, R. (2006). SPSS for psychologists: A guide to data analysis using: SPSS for windows, $3^{\text {rd }}$ ed., Palgrave Macmillan.

Cao, H., \& Zhang, S.Y. (2010). Analysis of the main interests of agricultural insurance main body based on the perspective of evolutionary game. Agriculture and Agricultural Science Procedia, 1, 354-363.

Cole, J.B., \& Gibson, R. (2010). Analysis and feasibility of crop revenue insurance in China. Agriculture and Agricultural Science Procedia, 1, 136-145

Cronbach, L. J. (1951). Coefficient alpha and the internal structure of tests: Psychometrika, 16(3), 297-334.

Dick, W.J.A., \& Wang, W. (2010). Government interventions in agricultural insurance. Agriculture and Agricultural Science Procedia, 1, 4-12.

Hart, C.E., Babcock, B.A., \& Hayes, D.J. (2001). Livestock revenue insurance. Journal of Futures Markets, 21, 553-580.

Hau, A. (2006). Production under uncertainty with insurance or hedging. Insurance, Mathematics and Economics, 38, 347-359.

Just, R.E., Calvin, L., \& Quinggin, J. (1999). Adverse selection in crop insurance: Actuarial and asymmetric information, incentives. American Journal of Agricultural Economics, 81(4), 834849. 
Juyun, Y. (2010). The Optimization path and integration mechanism of agricultural insurance in the charge of government. Agriculture and Agricultural Science. Procedia, 1, 258-261.

Likert, R. (1932). A Technique for the Measurement of Attitudes : Archives of Psychology, 140, 155.

Machnes, Y. (1995). Deductible insurance and production. Insurance: Mathematics and Economics, 17, 119-123.

Mahul, O., \& Vermersch, D. (2000). Hedging crop risk with yield insurance futures and options. European Review of Agricultural Economics, 27, 109-126.

Nelson, C.H., \& Loehman, E.T. (1987). Further toward a theory of agricultural insurance. American Journal of Agricultural Economics, 69, 523-531.

Pasaribu, S.M. (2010). Developing rice farm insurance in Indonesia. Agriculture and Agricultural Science Procedia, 1, 33-41

Qing-song, W. (2010). The farmers behavior in agricultural insurance under the Von-NeumanMorgenstern utility model. Agriculture and Agricultural Science Procedia, 1, 226-229.

Qingshui, F., \& Xuewei, Z. (2010). Development strategies on agricultural insurance under the building of new countryside. Agriculture and Agricultural Science Procedia, 1, 13-23.

Yang, Y. (2010). Weather index derivatives in risk transfer for agricultural natural hazards. Agriculture and Agricultural Science Procedia, 1, 100-105.

Yang, R., Wang, L., \& Xian, Z. (2010). Evaluation on the efficiency of crop insurance in China's major grain-producing area. Agriculture and Agricultural Science Procedia, 1, 90-99

Yuanchang, X., \& Jiyu, J. (2010). The optimal boundary of political subsidies for agricultural insurance in welfare economic prospect. Agriculture and Agricultural Science Procedia, 1, 2010, 163-169.

Wang, E., Yu, Y., Little, B.B., \& Li, Z. (2010). Crop Insurance Premium Design Based on Survival Analysis Model. Agriculture and Agricultural Science Procedia, 1, 67-75.

Wong, K.P. (2002). Production decisions in the presence of options: A Note. International Review of Economics and Finance, 11, 17-25.

Sai, T., Yulian, W., \& Xiaofeng, H. (2010). An Empirical Study of Agricultural Insurance-Evidence from China. Agriculture and Agricultural Science Procedia, 1, 62-66

Zeng, Y., \& Mu, Y. (2010). Development Evaluation of China's Policy-oriented Agricultural Insurance: Based on the Realization Degree of Policy Objectives. Agriculture and Agricultural Science Procedia, 262-270. 